
\title{
and Type 2 Diabetes: A Meta-analysis
}

\author{
Audrey Villard , Lucien Marchand ${ }^{2, *}$, Charles Thivolet $^{1,2}$, and Sophie Rome \\ CarMen laboratory (UMR INSERM 1060, INRA 1397, INSA), University of Lyon, Faculty o
}

Type 2 diabetes mellitus (T2DM) is the most common metabolic disorder worldwide. Because of ffected individuals is increasing at worrisome rates. While both environmental and genetic factor in delaying onset of diabetes, and studies antiabetic reatment. A total of 26 studies were enrolled in the global meta-analysis. Candidate miRNAs miR-17, miR-652) and 7 miRNAs in blood of obese subjects were identified (increased: his review, we found a strong discrepancy between miRNA detection and quantification analytical challenges are also discussed.

\footnotetext{
This is an open-access article distributed under the terms of the Creative Commons Attribution License, which permits unrestricted use, distribution, and reproduction in any medium, provided the original author and source are credited.

"Corresponding authors: Sophie Rome, Faculty of Medicine Lyon-Sud, Chemin du Grand Revoyet, 69600 Oullins, France, Tel: (33)

42623 5920; Fax: (33) 2623 5916; sophie.rome@univ-lyon1.fr.

\#Both participated equally to the study

The authors declare that there are no other conflicts of interest.
} 


\section{Keywords}

Circulating miRNAs; Type 2 diabetes; Obesity; Meta-analysis

\section{Introduction}

Type 2 diabetes mellitus (T2DM) is the most common metabolic disorder worldwide.

Because of population aging and increasing trends toward obesity and sedentary lifestyles, the number of affected individuals is increasing at worrisome rates and is expected to double within the next 20 years [1]. While both environmental and genetic factors are known to contribute to the development of T2DM, continuous research is needed to identify specific biomarkers that could aid both in prevention of the disease and development of new therapeutic options. In that context, circulatory miRNAs are considered as potential biomarkers. MiRNAs are a class of evolutionally conserved noncoding RNAs of 19-22 nucleotides and function as negative regulators of gene expression [2]. Functional analysis of miRNA target genes have shown that they play a major role in the regulation of developmental processes including cell growth and differentiation and programmed cell death by targeting preferentially signaling pathways and transcription factors [3,4]. In addition, important roles of miRNAs have emerged in the control of metabolic pathways involved in lipid metabolism, adipocyte differentiation, energy homeostasis, glucosestimulated insulin secretion and inflammation [5]. Thus, as a consequence of the various processes they are able to influence, miRNA deregulation is a hallmark of several pathological conditions, including cancer [6], inflammation [7], neurological disorders [8], cardiovascular diseases [9] and metabolic disorders [10].

In 2008, several independent groups described the presence of significant amounts of miRNAs in extracellular human body fluids [11-14]. These extracellular circulating miRNAs are surprisingly stable and can resist to unfavorable physiological conditions such as extreme variations in $\mathrm{pH}$, boiling, multiple freeze thaw cycles, and extended storage, despite high extracellular RNAse activities [15] because they are enclosed in small vesicles (e.g. in exosomes [16], shedding vesicles [16], apoptotic bodies [17]) or associated with, or packaged within, high-density lipoprotein and RNA-binding proteins $[18,19]$. The functional role of miRNAs in extracellular fluids is not yet precisely established. It has been demonstrated that miRNAs associated with exosomes or microvesicles can be delivered to neighboring cells, where they are able to regulate gene expression [16]. A recent study suggests that vesicle-free miRNAs can transfect cell exosomes that then transfer miRNA cargo to the acceptor cells [20]. These data raise the intriguing possibility of the involvement of these small RNA molecules in a new cell-to-cell communication mode [16].

Previous studies further indicate that the level and composition of these extracellular/ circulating miRNAs correlates well with diseases or injurious conditions [12,21-23]. A global survey of the miRNA distribution in 12 human body fluids (i.e. amniotic fluid, breast milk, bronchial lavage, cerebrospinal fluid, colostrum, peritoneal fluid, plasma, pleural fluid, saliva, seminal fluid, tears and urine) showed distinct compositions in different fluid types [14]. Notably, the miRNA spectrum in plasma is different from that of most of the other 
body fluids suggesting that extracellular miRNAs are not only passively released outside the cells. Indeed it has been demonstrated that some miRNAs are selectively exported or retained within the cell [24].

Circulatory miRNAs are now considered as potential biomarkers because they are stable and resistant and are modified under different pathophysiological conditions [25]. This prompted several groups to assess the predictive value of changes incirculatory miRNAs in type 2 diabetes associated or not with obesity. Here, we performed a meta-analysis to summarize all the results from available studies, aiming to determine the prognostic/diagnostic value of circulating miRNAs in blood of volunteers suffering from obesity and T2DM.

\section{Methods}

\section{Literature search}

Figure 1 summarizes the search strategy flow. MEDLINE (http://www.ncbi.nlm.nih.gov/ pubmed) was systematically searched to identify relevant studies combining the key words "miRNAs", "circulating", "diabetes", or/and "obesity", physical activity, biatric surgery and treatment, in humans. Articles were excluded if they were non-english articles, review, letters, economic analyses, or based on in vitro studies. Eligible studies enrolled participants diagnosed with pre-diabetes, diabetes and/or obesity, or patient under lifestyle interventions (e.g. physical activity), medical treatments or after bariatric surgery. The considered biological fluids were serum, plasma or whole blood. Studies on tissues samples or cell line were excluded.

\section{Data extraction}

We extracted trial features (authors, published year, and countries), patients characteristics (age, gender, number, glycemic status and BMI), RNA extraction methods, RNA detection methods, and the subset of miRNA differentially expressed between two conditions, with fold change when available.

\section{Bioinformatic analysis}

MiRNA target genes and significantly enriched KEGG pathways were predicted by bioinformatics by using DIANA-miRPath (http://diana.imis.athenainnovation.gr/DianaTools/ index.php?r=site/index) [26].

\section{Results}

In this review we have compiled all published data on circulating miRNAs quantified in blood of obese, pre-diabetic, diabetic and healthy controls and after lifestyle interventions, in order to identify candidate circulating miRNAs related to obesity and/or diabetes. Selected candidate miRNAs were defined as those revalidated by specific PCRassays in larger cohortes, after the initial screening using technologies based on large scale analysis (i.e.; microarray, PCR Low Density Array, sequencing) and reported in at least 2 studies and with the same direction of differential expression. 


\section{Studies included in the meta-analysis}

On a total of 72 articles retrieved from PubMed, 26 studies were included in the global meta-analysis (Figure 1 and Supplementary Table 1). These studies compared circulating miRNA levels between two conditions (obese vs controls, diabetes or pre-diabetes vs controls) or the effect of lifestyle interventions (i.e.; evaluation of miRNA concentrations before and after exercise, metformine treatment or bypass surgery). These studies involved both Caucasian [26-39] and Asian populations [40-51].

Then we separated the data according the characteristics of the patients; i.e.; 6 studies compared miRNA levels between obese vs lean subjects [29,32-34,45,48], 8 studies compared pre-diabetics patients vs control subjects [39-42,44,46 49,50], 14 studies compared diabetic vs BMI-matched non-diabetic subjects [26,28,30-32,39-47]. Among those 14 studies, only one has determined the effect of obesity on the concentration of circulating miRNAs [28] in T2DM patients.

As it is known that pre-analytical steps are important parameters that can affect miRNA detection and quantification [52,53], we indicated the different methods used for total RNA extraction for miRNA profiling in either serum $(n=10)$, plasma $(n=12)$ or wholeblood $(n=4)$ (Supplementary Table 2). The majority of the studies used commercial extraction kits including column-based purification step as miR-Vana ${ }^{\mathrm{TM}} P A R I S^{\mathrm{TM}}$ kit (Lifetechnologies), RiboPure ${ }^{\mathrm{TM}}$-Blood kit (Ambion), miR-Neasy-mini kit (Qiagen), microRNAextraction kit (Benevbio), Masterpure ${ }^{\mathrm{TM}}$ complete DNA-RNA purification kit $\left(\right.$ Epicentre $\left.^{\circledR}\right)$, miRCURY Biofluids miRNA kit (Exiqon) (Ambion) or QiAamp Circulating Nucleic Acid kit(Qiagen). Two studies used the canonical phenol-chloroform method. Finally, one study performed miRNA profiling directly on blood without RNA extraction [41]. In addition, the reverse transcription procedure was either based on poly-A-tailing or stem-loop, followed by either Taqman qPCR assay or Locked Nucleic Acid ( $L N A^{\mathrm{TM}}$ ) PCR (Supplementary Table 2).

\section{Circulating miRNA profiling in the context of obesity}

Circulating miRNA concentration was determined either in adult obese patients (5 studies) or in children of 7-10 years old (1 study) (Supplementary Table 3). Among the 47 circulating miRNAs that were found differentially expressed in blood between obese and non-obese subjects, 11 were identified in at least 2 different studies (miR-221, miR-142-3p, miR-125, miR-140-5p, miR-222, miR-103, miR-21-5p, miR-423-5p, miR-532-5p, miR-122-5p, miR-130b-3p). Among these 11 miRNAs, 7 were found to change in the same direction between obese vs nonobese patients (increased: miR-142-3p, miR-140-5p, miR-222; decreased: miR-21, miR-221, miR-125b, mir-103) (Table 1). Their target genes were predicted by using DIANAmicroT-CDS algorithm. This algorithm identifies miRNA binding sites located in both the $3^{\prime}$-UTR and coding sequence regions [54]. Then DIANAmiRPath was used to identify significantly regulated KEGG pathways by the selected miRNA [55]. As shown on Figure 2, the 7 miRNAs altered in the blood of obese patients vs lean subjects were predicted to target genes involved in various cancers, cell cycle, brain functions, immune response, lipid and protein metabolism, signaling pathways, pancreatic secretion and circadian clock. 


\section{Circulating miRNA profiling in the context of prediabetes}

Concentrations of circulating miRNAs between pre-diabetic patients and control subjects has been determined in 7 studies (Supplementary Table 4). We have considered the study of Zhao et al. [50] which included pregnant women with or without gestational diabetes, the latter being considered as pre-diabetic patients. Among the 16 miRNAs identified, 4 were at least identified in 2 different studies (miR-29a, miR-192, miR-150, and miR-126). Only 3 were differentially expressed in the same direction in pre-diabetic vs control subjects (miR-29a, miR-192 and miR-126).

\section{miRNA profiling in the context of diabetes}

Concentration of circulating miRNAs in blood of diabetic patients vs healthy subjects was determined in 14 studies (Supplementary Table 1); 6 involved Caucasian populations and 8 was made on Asian subjects. Of note, 2 studies were conducted only on men [28,44]. In addition, diabetes duration was different among the studies, i.e.; newly diagnosed diabetic patients [32,40,44-47], or long-term diabetic subjects [26,28,30,31,39,41-43], and 3 studies involved obese diabetic patients [28,31,39]. A total of 113 miRNAs were found differentially expressed in blood of diabetic patients vs healthy subjects (Supplementary Table 5). Among them, 20 were at least identified in 2 different studies (miR-320a, miR-150, miR-126, miR-197, miR-20b, miR-146a, miR-142-3p, miR-222, miR-192, miR-17, miR-652, miR-29a, miR-27a, miR-375, miR-29b, miR-15a, miR-21, miR-24, miR-125b, miR-30d). Half of them was modulated in the same direction in at least 2 studies (increased: miR-320a, miR-142-3p, miR-222, miR-29a, miR-27a, miR-375; decreased: miR-197, miR-20b, miR-17, miR-652) (Table 2). MiR-320a and miR-375 were identified in 3 studies and displayed the highest fold changes between diabetics and control subjects (Table 2). Predicted significant KEGG pathways affected by these 10 miRNAs are shown on Figure 3. They were related to cell cycle, brain functions including 5 brain diseases, immunity, signaling pathways, metabolism (amino acid, vitamin, glycan and lipid), heart alterations, circadian rhythm.

\section{Modification of circulating miRNAs concentrations after interventions}

Because lifestyle is a well-known key contributor to the global obesity and diabetes epidemics, we postulated that altered circulating miRNA concentrations identified in obese and/ordiabetic subjects would be also regulated by physical activity [56]. In this analysis we have included 5 studies reporting an effect of physical activity on the concentrations of circulating miRNAs identified above as altered either in obese subjects, pre-diabetic ordiabetic patients vs controls (Tables 1 and 2) [36-39,51]. As shown on Table 3, the level of miR-222, which is decreased in pre-diabetic vs healthy patients, was increased by physical activity, in healthy subjects. In addition levels of miR-21 and miR-221 affected in obese subjects were increased in lean subjects after physical activity. Interestingly, these 2 miRNAs were also positively regulated by bariatric surgery in non obese subjects. The level of miR-140-5p, which was increased in the plasma of obese or diabetic subjects compared to controls, was decreased after treatment with metformin or bariatric surgery indicating that the circulating concentration of this miRNA was strongly correlated with insulin sensitivity. Moreover, the level of miR-192 and miR-193b, which were increased in the serum of pre- 
diabetic subjects, returned to baseline after therapeutic intervention consisting in chronic excercice.

\section{Discussion}

Ideal biomarkers should be easily accessible by minimally invasive sampling procedure making routine blood, urine or saliva excellent source of choice. Among these biofluid, a substantial number of studies have demonstrated that the level of blood miRNAs is affected in a wide range of disorders including heart failure [9], drug-induced liver injury [57], cancers [58] and neurological disorders [59]. In the context of diabetes mellitus (T2DM), the discovery of biomarkers heralding the early stages of diabetes progression would allow for the implementation of preventive therapies, which are more successful if high-risk individuals are identified at early stage. For instance, it is increasingly recognized that the risk of cardiovascular diseases (CVD) is greater in patients with diabetes and other cardiometabolic risk (CMR) factors than in those with diabetes alone. The identification of these high-risk CMR patients could permit to provide specific recommendations and treatment at early stage of CVD. In addition, biomarkers would help in monitoring response to interventions (e.g.; diet or lifestyle interventions) [60]. Therefore during the last 5 years, several studies have been conducted to test whether the concentrations of circulating miRNAs were affected in patients suffering from obesity and/or T2DM.

At first, we found that although more than 2,000 miRNAs have been described in the human genome, only hundred of them are routinely identified in human serum/plasma samples. In agreement Blondal et al. [61] identified only 119 miRNAs consistently expressed in 1,500 serum and plasma samples, suggesting that whatever the pathology considered, it seems that we have access to only a small subset of miRNAs in the blood to characterize different unrelated diseases (e.g.; cancer, diabetes). It is thus not surprising that a significant number of miRNAs listed in this review have been also identified in the blood of patients suffering from unrelated pathologies (e.g.; the circulating level of miR-21 is altered both in patients suffering from various cancers [62-64] and from obesity and/or T2DM [26,27,30,39]). As shown on Supplementary Table 6, 112 KEGG pathways were predicted to be collectively targeted by the 119 miRNAs commonly identified in the human blood [61]. Among them, the PI3K-Akt signaling pathway (hsa04151), which is involved both in cellular proliferation of cancer cells and in insulin response in insulin-targeted tissues [65], contains the highest number of circulating miRNA target genes. It is now well-admitted that some cancers develop more commonly in obese patients or/and suffering from T2DM, such as cancers of the liver, pancreas, and endometrium [66,67]. Thus altered circulating miRNA levels in obese/T2DM patients might be considered as bad prognosis for the development of these cancers. In line with this hypothesis, some of the dysregulated miRNAs in obese patients are involved in endometrial (miR-103) [68] and pancreatic cancers (miR-142-3p, miR-103, miR-21) [69,70] (Figure 2).

The second observation is that although 26 studies were taken into account in this review, very few miRNAs appeared to be modulated consistently in the same direction across these studies. This result is likely due to the absence of pre-analytical considerations that are important to take into account before miRNA screening, e.g.; serum vs plasma [71], methods 
used for RNA isolation [72], methods for miRNA screening (microarray, Low density array, sequencing) [73], technologies for validation by qRT-PCR [74] and data normalization [75]. Particularly, the circulating levels of some miRNAs are affected by hemolysis $[53,76]$. Beside these 'technical' considerations it has also been demonstrated that miRNAs might have sex-specific association with metabolic syndrome [77,78]. Considering both men and women in the same studies for miRNA screening might explain part of the differences among the data. In addition, we have pooled studies involving Caucasian and Indian populations. However, it is admitted that despite having lower body weight, Asian populations are more likely than Caucasians to have T2DM and have specific nutritional habits [79]. As a consequence, circulating miRNAs identified in caucasian T2DM populations might not be relevant for Asian populations [40].

At last, it has been found that the majority of blood miRNAs is vesicle-free [80,81]. The remaining are exported in extracellular vesicles (i.e. exosomes and microparticles) and it is has recently been demonstrated that cells selectively export subsets of miRNAs in vesicles [24]. Thus the global analysis of circulating miRNAs might result in a complex signature that superimposed different miRNAs variations according to their mode of secretion. A recent study demonstrated that the level of some specific exosomal proteins was positively related to metabolic complications of obesity suggesting that concomitantly the level of specific exosomal miRNAs might also variate [82]. Therefore we suggest that it would be more appropriate to analyze each serum/plasma fractions independently (i.e. exosomes, microparticles, HDL/LDL and vesicle-free miRNAs) to identify specific and relevant miRNAs patterns that may be masked among the entire miRNA blood profile.

In order, to take into account that all these pre-analytical parameters may have affected the identification of altered circulating miRNAs in the context of obesity and/or T2DM, candidate miRNAs selected in this review are defined as those reported in at least 2 studies with same direction of differential expression. Ten miRNAs altered in blood of patients suffering from T2DM were identified (increased: miR-320a, miR-142-3p, miR-222, miR-29a, miR-27a, miR-375; decreased: miR-197, miR-20b, miR-17, miR-652) and 7 miRNAs in blood of obese subjects were identified (increased: miR-142-3p, miR-140-5p, miR-222; decreased: miR-21-5p, miR-221-3p, miR-125-5p, mir-103-5p). Both groups of patients had elevated expression of circulating miR-142-3p and miR-222. MiR-142-3p was recently reported as dysregulated in blood of T2DM in a meta-analysis pooling miRNA studies on tissues, blood/serum both in human and animals [83]. At the tissue level, functional analyses have shown that miR-142-3p inhibits cancer cell proliferation [84], works as a tumor suppressor [85,86], enhances degranulation in mast cells [87], and is involved in the regulation of circadian clock through the control of Bmal1 expression $[88,89]$.

Six miRNAs were differentially expressed both in newly diagnosed diabetic patients [44,46] and long-term diabetic subjects [26,28,30,43,44] (i.e.; miR-142-3p, miR-222, miR-320a, miR-197, miR-20b, miR-375) suggesting that their alterations is not related to metabolic complications associated with T2DM (e.g.; advanced beta-cell failure) but are representative of early events associated with the physiopathology of the disease. Among these 6 miRNAs, 5 (miR-142-3p, miR-222, miR-320a, miR-197, miR-20b) were differentially expressed both 
in Caucasian [28,30] and Asian population [26,44]. Differences in duration of diabetes (newly diagnosed diabetic patients $v s$ long-term diabetic subjects) might also explain difference in expression of circulating miRNAs, because metabolic alterations may be different in subjects with recent diabetes compared to subjects with advanced beta-cell failure.

Dysregulated miRNAs identified in this study (Tables 1-3) are expressed in all tissues and thus cannot reflect specific homeostasis alterations in a given insulin-sensitive tissue (e.g.; liver, skeletal muscle adipose tissue). Computational predictions of target genes followed by functional GO enrichment analysis indicated a relevant role of these miRNAs in modulating the expression of genes involved in biological pathways that are well-known to be affected both in obese/T2DM subjects (i.e. pancreatic secretion, brain functions, signaling pathways, lipid and protein metabolism, circadian rhythm and cell cycle). This suggested that miRNAs identified in this study can only be considered as indicators of onset/progression of these metabolic diseases. Interestingly, functions such as 'brain disorders' and 'heart alteration' were targeted only by miRNAs altered in T2DM patients (Figure 3). Insulin resistance, increased inflammation and impaired metabolism are key pathological features of both neurodegenerative disorders (ND) and diabetes [90-95]. However, the precise mechanisms involved in ND development in T2DM patients are not yet fully understood. It would be interesting to determine whether decreased circulating level of miR-17-5p and miR-652-3p could be correlated with furtur neurological alterations in T2DM patients. As shown on Figure 3, miR-320a, miR-29a-3p and miR-126-3p target genes are predicted to be involved in cardiac arrhythmia, dilated cardiomyopathy and heart hypertrophy. Reduced concentrations of plasma miR-126 and increased levels of miR-320a have been demonstrated as potential markers predicting diabetic vascular and myocardial complications [26]. It now important to determine whether these results can be exploited for miRNA-based therapeutic interventions of vascular complications associated with T2DM [17].

A recent meta-analysis indicated that lifestyle intervention (e.g.; diet, exercise...) showed significant benefit in risk factors that are known to be associated with development of cardiovascular disease in patients with T2DM [96]. Therefore, we expected that these interventions would have an impact on the circulating concentrations of miRNAs altered in pre-diabetic and T2DM. In addition we also analyzed whether insulin sensitizing drug such as metformin and bariatric surgery, known to restore metabolic functions, would also modify the concentrations of circulating miRNAs. Interestingly, the levels of some altered blood miRNAs in T2DM patients were restored by metformin treatment (miR-140-5p, miR-222) or after bariatric surgery (miR-142-3p, miR-140-5p, miR- 21, miR-423-5p). In addition physical activity has also an impact on the levels of relevant circulating miRNAs such as miR-21, miR-126, miR-192, miR-193b and miR-221 in diabetic and/prediabetic patients. These data suggest that circulating miRNA signature could also monitor response to interventions. 


\section{Conclusion}

Although there is a lot of discrepancy among the 26 studies included in this meta-analysis, we have identified 10 miRNAs altered in blood of patients suffering from T2DM and 7 miRNAs dysregulated in blood of obese subjects. It is now urgent to validate these miRNAs in larger cohorts of patients taking into account all pre-analytical parameters that may introduce variability in the data. Moreover, it is also important to clearly identify whether the level of these miRNAs (either individually or in combination) might be use to validate the effect of treatment or lifestyle interventions. A change in blood level after intervention would strengthen their values as biomarkers.

\section{Supplementary Material}

Refer to Web version on PubMed Central for supplementary material.

\section{Acknowledgments}

Professor Charles Thivolet belongs to the nPOD network, a collaborative diabetes research project sponsored by the Juvenile Diabetes Research Foundation (JDRF) and NIH (P01 AI42288). In this network, Pr. Charles Thivolet is associated to the project 'novel Biomarkers'.

\section{References}

1. Kharroubi AT, Darwish HM. Diabetes mellitus: The epidemic of the century. World J Diabetes. 2015; 6:850-867. [PubMed: 26131326]

2. Bartel DP. MicroRNAs: genomics, biogenesis, mechanism, and function. Cell. 2004; 116:281-297. [PubMed: 14744438]

3. Cui Q, Yu Z, Purisima EO, Wang E. Principles of microRNA regulation of a human cellular signaling network. Mol Syst Biol. 2006; 2:46. [PubMed: 16969338]

4. Stark A, Brennecke J, Bushati N, Russell RB, Cohen SM. Animal MicroRNAs confer robustness to gene expression and have a significant impact on 3'UTR evolution. Cell. 2005; 123:1133-1146. [PubMed: 16337999]

5. Lynn FC. Meta-regulation: microRNA regulation of glucose and lipid metabolism. Trends Endocrinol Metab. 2009; 20:452-459. [PubMed: 19800254]

6. Lages E, Ipas H, Guttin A, Nesr H, Berger F, Issartel JP. MicroRNAs: molecular featuresand role in cancer. Front Biosci. 2012; 17:2508-40.

7. O'Connell RM, Rao DS, Baltimore D. microRNA regulation of inflammatory responses. Annu Rev Immunol. 2012; 30:295-312. [PubMed: 22224773]

8. Salta E, De Strooper B. Non-coding RNAs with essential roles in neurodegenerative disorders. Lancet Neurol. 2012; 11:189-200. [PubMed: 22265214]

9. Van Aelst LN, Heymans S. MicroRNAs as biomarkers for ischemic heart disease. J Cardiovasc Transl Res. 2013; 6:458-470. [PubMed: 23716129]

10. Dehwah MA, Xu A, Huang Q. MicroRNAs and type 2 diabetes/obesity. J Genet Genomics. 2012; 39:11-18. [PubMed: 22293113]

11. Lawrie CH, Gal S, Dunlop HM, Pushkaran B, Liggins AP, et al. Detection of elevated levels of tumour-associated microRNAs in serum of patients with diffuse large B-cell lymphoma. British journal of haematology. 2008; 14:672-675. [PubMed: 18318758]

12. Mitchell PS, Parkin RK, Kroh EM, Fritz BR, Wyman SK, et al. Circulating microRNAs as stable blood-based markers for cancer detection. Proceedings of the National Academy of Sciences of the United States of America. 2008; 105:10513-10518. [PubMed: 18663219] 
13. Chen X, Ba Y, Ma L, Cai X, Yin Y, et al. Characterization of microRNAs in serum: a novel class of biomarkers for diagnosis of cancer and other diseases. Cell Res. 2008; 18:997-1006. [PubMed: 18766170]

14. Weber JA, Baxter DH, Zhang S, Huang DY, Huang KH, et al. The microRNA spectrum in 12 body fluids. Clin Chem. 2010; 56:1733-1741. [PubMed: 20847327]

15. Köberle V, Pleli T, Schmithals C, Augusto Alonso E, Haupenthal J, et al. Differential stability of cell-free circulating microRNAs: implications for their utilization as biomarkers. PLoS One. 2013; 8:e75184. [PubMed: 24073250]

16. Valadi H, Ekström K, Bossios A, Sjöstrand M, Lee JJ, et al. Exosome-mediated transfer of mRNAs and microRNAs is a novel mechanism of genetic exchange between cells. Nat Cell Biol. 2007; 9:654-659. [PubMed: 17486113]

17. Zernecke A, Bidzhekov K, Noels H, Shagdarsuren E, Gan L, et al. Delivery of microRNA-126 by apoptotic bodies induces CXCL12-dependent vascular protection. Sci Signal. 2009; 2:ra81. [PubMed: 19996457]

18. Vickers KC, Palmisano BT, Shoucri BM, Shamburek RD, Remaley AT. MicroRNAs are transported in plasma and delivered to recipient cells by high-density lipoproteins. Nat Cell Biol. 2011; 13:423-433. [PubMed: 21423178]

19. Wang K, Zhang S, Weber J, Baxter D, Galas DJ. Export of microRNAs and microRNA-protective protein by mammalian cells. Nucleic Acids Res. 2010; 38:7248-7259. [PubMed: 20615901]

20. Bryniarski K, Ptak W, Martin E, Nazimek K, Szczepanik M, et al. Free Extracellular miRNA Functionally Targets Cells by Transfecting Exosomes from Their Companion Cells. PLoS One. 2015; 10:e0122991. [PubMed: 25923429]

21. Melman YF, Shah R, Danielson K, Xiao J, Simonson B, et al. CirculatingMicroRNA-30d is Associated with Response to Cardiac Resynchronization Therapy in HeartFailure and Regulates Cardiomyocyte Apoptosis: A Translational Pilot Study. Circulation 2015. 2015 May 20.

22. Li X, Khanna A, Li N, Wang E. Circulatory miR34a as an RNAbased, noninvasive biomarker for brain aging. Aging (Albany NY). 2011; 3:985-1002. [PubMed: 22064828]

23. Laterza OF, Lim L, Garrett-Engele PW, Vlasakova K, Muniappa N, et al. Plasma MicroRNAs as sensitive and specific biomarkers of tissue injury. Clin Chem. 2009; 55:1977-1983. [PubMed: 19745058]

24. Guduric-Fuchs J, O’Connor A, Camp B, O’Neill CL, Medina RJ, et al. Selective extracellular vesicle-mediated export of an overlapping set of microRNAs from multiple cell types. BMC Genomics. 2012; 13:357. [PubMed: 22849433]

25. Gilad S, Meiri E, Yogev Y, Benjamin S, Lebanony D, et al. Serum microRNAs are promising novel biomarkers. PLoS One. 2008; 3:e3148. [PubMed: 18773077]

26. Zampetaki A, Kiechl S, Drozdov I, Willeit P, Mayr U, et al. Plasma microRNA profiling reveals loss of endothelial miR-126 and other microRNAs in type 2 diabetes. Circ Res. 2010; 107:810817. [PubMed: 20651284]

27. Ortega FJ, Mercader JM, Catalán V, Moreno-Navarrete JM, Pueyo N, et al. Targeting the circulating microRNA signature of obesity. See comment in PClin Chem. 2013; 59:781-792.

28. Ortega FJ, Mercader JM, Moreno-Navarrete JM, Rovira O, Guerra E, et al. Profiling of circulating microRNAs reveals common microRNAs linked to type 2 diabetes that change with insulin sensitization. Diabetes Care. 2014; 37:1375-1383. [PubMed: 24478399]

29. Prats-Puig A, Ortega FJ, Mercader JM, Moreno-Navarrete JM, Moreno M, et al. Changes in circulating microRNAs are associated with childhood obesity. J Clin Endocrinol Metab. 2013; 98:E1655-1660. [PubMed: 23928666]

30. Wang X, Sundquist J, Zöller B, Memon AA, Palmér K, et al. Determination of 14 circulating microRNAs in Swedes and Iraqis with and without diabetes mellitus type 2. PLoS One. 2014; 9:e86792. [PubMed: 24497980]

31. Santovito D, De Nardis V, Marcantonio P, Mandolini C, Paganelli C, Vitale E, et al. Plasma exosome microRNA profiling unravels a new potential modulator of adiponectin pathwayin diabetes: effect of glycemic control. The Journal of clinical endocrinology and metabolism. 2014; 99:E1681-5. [PubMed: 24937531] 
32. Pescador N, Pérez-Barba M, Ibarra JM, Corbatón A, Martínez-Larrad MT, et al. Serum circulating microRNA profiling for identification of potential type 2 diabetes and obesity biomarkers. PLoS One. 2013; 8:e77251. [PubMed: 24204780]

33. Heneghan HM, Miller N, McAnena OJ, O’Brien T, Kerin MJ. Differential miRNA expression in omental adipose tissue and in the circulation of obese patients identifies novel metabolic biomarkers. J Clin Endocrinol Metab. 2011; 96:E846-850. [PubMed: 21367929]

34. Murri M, Insenser M, Fernandez-Duran E, San-Millan JL, Escobar-Morreale HF. Effects of polycystic ovary syndrome (PCOS), sex hormones, and obesity on circulating miRNA-21, miRNA-27b, miRNA-103, and miRNA-155 expression. The Journal of clinical endocrinology and metabolism. 2013; 98:E1835-44. [PubMed: 24037889]

35. Mooren FC, Viereck J, Krüger K, Thum T. Circulating microRNAs as potential biomarkers of aerobic exercise capacity. Am J Physiol Heart Circ Physiol. 2014; 306:H557-563. [PubMed: 24363306]

36. Baggish AL, Park J, Min PK, Isaacs S, Parker BA, et al. Rapid upregulation and clearance of distinct circulating microRNAs after prolonged aeroc exercise. J Appl Physiol. 2014; 116:522531. [PubMed: 24436293]

37. Uhlemann M, Möbius-Winkler S, Fikenzer S, Adam J, Redlich M, et al. Circulating microRNA-126 increases after different forms of endurance exercise in healthy adults. Eur J Prev Cardiol. 2014; 21:484-491. [PubMed: 23150891]

38. Baggish AL, Hale A, Weiner RB, Lewis GD, Systrom D, et al. Dynamic regulation of circulating microRNA during acute exhaustive exercise and sustained aerobic exercise training. J Physiol. 2011; 589:3983-3994. [PubMed: 21690193]

39. Párrizas M, Brugnara L, Esteban Y, González-Franquesa A, Canivell S, et al. Circulating miR-192 and miR-193b are markers of prediabetes and are modulated by an exercise intervention. $\mathrm{J}$ Clin Endocrinol Metab. 2015; 100:E407-415. [PubMed: 25532038]

40. Prabu P, Rome S, Sathishkumar C, Aravind S, Mahalingam B, et al. Circulating MiRNAs of 'Asian Indian Phenotype' Identified in Subjects with Impaired Glucose Tolerance and Patients with Type 2 Diabetes. PLoS One. 2015; 10:e0128372. [PubMed: 26020947]

41. Liu Y, Gao G, Yang C, Zhou K, Shen B, et al. The role of circulating microRNA-126 (miR-126): a novel biomarker for screening prediabetes and newly diagnosed type 2 diabetes mellitus. Int J Mol Sci. 2014; 15:10567-10577. [PubMed: 24927146]

42. Zhang T, Lv C, Li L, Chen S, Liu S, et al. Plasma miR-126 is a potentialbiomarker for early prediction of type 2 diabetes mellitus in susceptible individuals. BioMedresearch International. 2013; 2013:761617.

43. Higuchi C, Nakatsuka A, Eguchi J, Teshigawara S, Kanzaki M, et al. Identification of circulating miR-101, miR-375 and miR-802 as biomarkers for type 2 diabetes. Metabolism. 2015; 64:489497. [PubMed: 25726255]

44. Karolina DS, Armugam A, Tavintharan S, Wong MT, Lim SC, et al. MicroRNA 144 impairs insulin signaling by inhibiting the expression of insulin receptor substrate 1 in type 2 diabetes mellitus. PLoS One. 2011; 6:e22839. [PubMed: 21829658]

45. Karolina DS, Tavintharan S, Armugam A, Sepramaniam S, Pek SL, et al. Circulating miRNA profiles in patients with metabolic syndrome. J Clin Endocrinol Metab. 2012; 97:E2271-2276. [PubMed: 23032062]

46. Kong L, Zhu J, Han W, Jiang X, Xu M, et al. Significance of serum microRNAsin pre-diabetes and newly diagnosed type 2 diabetes: a clinical study. Acta diabetologica. 2011; 48:61-9. [PubMed: 20857148]

47. Rong Y, Bao W, Shan Z, Liu J, Yu X, et al. Increased microRNA-146a levels inplasma of patients with newly diagnosed type 2 diabetes mellitus. PloS one. 2013; 8:e73272. [PubMed: 24023848]

48. Wang R, Hong J, Cao Y, Shi J, Gu W, et al. Elevated circulating microRNA-122is associated with obesity and insulin resistance in young adults. European journal of endocrinology/European Federation of Endocrine Societies. 2015; 172:291-300. [PubMed: 25515554]

49. Wang YT, Tsai PC, Liao YC, Hsu CY, Juo SH. Circulating microRNAs have a sex-specific association with metabolic syndrome. J Biomed Sci. 2013; 20:72. [PubMed: 24093444] 
50. Zhao C, Dong J, Jiang T, Shi Z, Yu B, et al. Early second-trimester serum miRNA profiling predicts gestational diabetes mellitus. PLoS One. 2011; 6:e23925. [PubMed: 21887347]

51. Sawada S, Kon M, Wada S, Ushida T, Suzuki K, et al. Profiling of circulating microRNAs after a bout of acute resistance exercise in humans. PLoS One. 2013; 8:e70823. [PubMed: 23923026]

52. Pritchard CC, Cheng HH, Tewari M. MicroRNA profiling: approaches and considerations. Nat Rev Genet. 2012; 13:358-369. [PubMed: 22510765]

53. Pritchard CC, Kroh E, Wood B, Arroyo JD, Dougherty KJ, et al. Blood cell origin of circulating microRNAs: a cautionary note for cancer biomarker studies. Cancer Prev Res (Phila). 2012; 5:492-497. [PubMed: 22158052]

54. Paraskevopoulou MD, Georgakilas G, Kostoulas N, Vlachos IS, Vergoulis T, et al. DIANA-microT web server v5.0: service integration into miRNA functional analysis workflows. Nucleic Acids Res. 2013; 41:W169-173. [PubMed: 23680784]

55. Vlachos IS, Zagganas K, Paraskevopoulou MD, Georgakilas G, Karagkouni D, et al. DIANAmiRPath v3.0: deciphering microRNA function with experimental support. Nucleic Acids Res. 2015; 43:W460-466. [PubMed: 25977294]

56. Wilson V. Reversing type 2 diabetes with lifestyle change. Nurs Times. 2015; 111:17-19. [PubMed: 26182553]

57. Wang K, Zhang S, Marzolf B, Troisch P, Brightman A, et al. Circulating microRNAs, potential biomarkers for drug-induced liver injury. Proc Natl Acad Sci U S A. 2009; 106:4402-4407. [PubMed: 19246379]

58. Ferracin M, Veronese A, Negrini M. Micromarkers: miRNAs in cancer diagnosis andprognosis. Expert review of molecular diagnostics. 2010; 10:297-308. [PubMed: 20370587]

59. Geekiyanage H, Jicha GA, Nelson PT, Chan C. Blood serum miRNA: non-invasive biomarkers for Alzheimer's disease. Exp Neurol. 2012; 235:491-496. [PubMed: 22155483]

60. Rome S. Use of miRNAs in biofluids as biomarkers in dietary and lifestyle intervention studies. Genes Nutr. 2015; 10:483. [PubMed: 26233309]

61. Blondal T, Jensby Nielsen S, Baker A, Andreasen D, Mouritzen P, et al. Assessing sample and miRNA profile quality in serum and plasma or other biofluids. Methods. 2013; 59:S1-6. [PubMed: 23036329]

62. Wu J, Li G, Wang Z, Yao Y, Chen R, et al. Circulating MicroRNA-21 Is a Potential Diagnostic Biomarker in Gastric Cancer. Dis Markers. 2015; 2015:435656. [PubMed: 26063956]

63. Gao J, Zhang Q, Xu J, Guo L, Li X. Clinical significance of serum miR-21 in breastcancer compared with CA153 and CEA. Chinese journal of cancer research $=$ Chung-kuo yencheng yen chiu. $2013 ; 25: 743-8$.

64. Li G, Pu Y. MicroRNA signatures in total peripheral blood of gallbladder cancer patients. Tumour Biol. 2015

65. Iguchi H, Kosaka N, Ochiya T. Secretory microRNAs as a versatile communication tool. Commun Integr Biol. 2010; 3:478-481. [PubMed: 21057646]

66. Giovannucci E, Harlan DM, Archer MC, Bergenstal RM, Gapstur SM, et al. Diabetes and cancer: a consensus report. Diabetes Care. 2010; 33:1674-1685. [PubMed: 20587728]

67. Gallagher EJ, LeRoith D. Obesity and Diabetes: The Increased Risk of Cancer and Cancer-Related Mortality. Physiol Rev. 2015; 95:727-748. [PubMed: 26084689]

68. Yu D, Zhou H, Xun Q, Xu X, Ling J, et al. microRNA-103 regulates the growth and invasion of endometrial cancer cells through the downregulation of tissue inhibitor of metalloproteinase 3 . Oncol Lett. 2012; 3:1221-1226. [PubMed: 22783422]

69. Chakraborty C, George Priya Doss C, Bandyopadhyay S. miRNAs in insulin resistanceand diabetes-associated pancreatic cancer: the 'minute and miracle' molecule moving as a monitorin the 'genomic galaxy'. Current drug targets. 2013; 14:1110-1117. [PubMed: 23834149]

70. MacKenzie TN, Mujumdar N, Banerjee S, Sangwan V, Sarver A, et al. Triptolide induces the expression of miR-142-3p: a negative regulator of heat shock protein 70 and pancreatic cancer cell proliferation. Mol Cancer Ther. 2013; 12:1266-1275. [PubMed: 23635652]

71. Wang K, Yuan Y, Cho JH, McClarty S, Baxter D, et al. Comparing the MicroRNA spectrum between serum and plasma. PLoS One. 2012; 7:e41561. [PubMed: 22859996] 
72. Moret I, Sánchez-Izquierdo D, Iborra M, Tortosa L, Navarro-Puche A, et al. Assessing an improved protocol for plasma microRNA extraction. PLoS One. 2013; 8:e82753. [PubMed: 24376572]

73. Leidner RS, Li L, Thompson CL. Dampening enthusiasm for circulating microRNA in breast cancer. PLoS One. 2013; 8:e57841. [PubMed: 23472110]

74. Roberts TC, Coenen-Stass AM, Wood MJ. Assessment of RT-qPCR normalization strategies for accurate quantification of extracellular microRNAs in murine serum. PLoS One. 2014; 9:e89237. [PubMed: 24586621]

75. Brunet-Vega A, Pericay C, Quílez ME, Ramírez-Lázaro MJ, Calvet X, et al. Variability in microRNA recovery from plasma: Comparison of five commercial kits. Anal Biochem. 2015; 488:28-35. [PubMed: 26271186]

76. Kirschner MB, Kao SC, Edelman JJ, Armstrong NJ, Vallely MP, et al. Haemolysis during sample preparation alters microRNA content of plasma. PloS one. 2011; 6:e24145. [PubMed: 21909417]

77. Wang K, Yuan Y, Li H, Cho JH, Huang D, et al. The spectrum of circulating RNA: a window into systems toxicology. Toxicol Sci. 2013; 132:478-492. [PubMed: 23358195]

78. Tarallo S, Pardini B, Mancuso G, Rosa F, Di Gaetano C, et al. MicroRNA expression in relation to different dietary habits: a comparison in stool and plasma samples. Mutagenesis. 2014; 29:385391. [PubMed: 25150024]

79. Gujral UP, Pradeepa R, Weber MB, Narayan KM, Mohan V. Type 2 diabetes in SouthAsians: similarities and differences with white Caucasian and other populations. Annals of theNew York Academy of Sciences. 2013; 1281:51-63.

80. Arroyo JD, Chevillet JR, Kroh EM, Ruf IK, Pritchard CC, et al. Argonaute2 complexes carry a population of circulating microRNAs independent of vesicles in human plasma. Proc Natl Acad Sci U S A. 2011; 108:5003-5008. [PubMed: 21383194]

81. Turchinovich A, Weiz L, Langheinz A, Burwinkel B. Characterization of extracellular circulating microRNA. Nucleic Acids Res. 2011; 39:7223-7233. [PubMed: 21609964]

82. Kranendonk ME, de Kleijn DP, Kalkhoven E, Kanhai DA, Uiterwaal CS, et al. Extracellular vesicle markers in relation to obesity and metabolic complications inpatients with manifest cardiovascular disease. Cardiovascular diabetology. 2014; 13:37. [PubMed: 24498934]

83. Zhu H, Leung SW. Identification of microRNA biomarkers in type 2 diabetes: a meta-analysis of controlled profiling studies. Diabetologia. 2015; 58:900-911. [PubMed: 25677225]

84. Deng B, Zhang Y, Zhang S, Wen F, Miao Y, et al. MicroRNA-142-3p inhibits cell proliferation and invasion of cervical cancer cells by targeting FZD7. Tumour Biol. 2015

85. Xu G, Wang J, Jia Y, Shen F, Han W, et al. MiR-142-3p functions as a potential tumor suppressor in human osteosarcoma by targeting HMGA1. Cell Physiol Biochem. 2014; 33:1329-1339. [PubMed: 24803022]

86. Shen WW, Zeng Z, Zhu WX, Fu GH. MiR-142-3p functions as a tumor suppressor by targeting CD133, ABCG2, and Lgr5 in colon cancer cells. J Mol Med (Berl). 2013; 91:989-1000. [PubMed: 23619912]

87. Yamada Y, Kosaka K, Miyazawa T, Kurata-Miura K, Yoshida T. miR-142-3p enhances FcÎ $\mu$ RImediated degranulation in mast cells. Biochem Biophys Res Commun. 2014; 443:980-986. [PubMed: 24361879]

88. Shende VR, Neuendorff N, Earnest DJ. Role of miR-142-3p in the post-transcriptional regulation of the clock gene Bmal1 in the mouse SCN. PLoS One. 2013; 8:e65300. [PubMed: 23755214]

89. Tan X, Zhang P, Zhou L, Yin B, Pan H. Clock-controlled mir-142-3p can targetits activator, Bmal1. BMC molecular biology. 2012; 13:27. [PubMed: 22958478]

90. Bedse G, Di Domenico F, Serviddio G, Cassano T. Aberrant insulin signaling in Alzheimer's disease: current knowledge. Front Neurosci. 2015; 9:204. [PubMed: 26136647]

91. Hao K, Di Narzo AF, Ho L, Luo W, Li S, et al. Shared genetic etiology underlying Alzheimer's disease and type 2 diabetes. Mol Aspects Med. 2015

92. Rosales-Corral S, Tan DX, Manchester L, Reiter RJ. Diabetes and Alzheimer disease, twooverlapping pathologies with the same background: oxidative stress. Oxidative medicine andcellular longevity: 985845.2015 
93. Hölscher C. Drugs developed for treatment of diabetes show protective effects in Alzheimer's and Parkinson's diseases. Sheng Li Xue Bao. 2014; 66:497-510. [PubMed: 25331995]

94. Zhang P, Tian B. Metabolic syndrome: an important risk factor for Parkinson's disease. Oxid Med Cell Longev. 2014; 2014:729194. [PubMed: 24955210]

95. Jawaid A, Brown JA, Schulz PE. Diabetes mellitus in amyotrophic lateral sclerosis: DrJekyll or Mr Hyde? Eur J Neurol. 2015

96. Tuomilehto J, Schwarz P, Lindström J. Long-term benefits from lifestyle interventions for type 2 diabetes prevention: time to expand the efforts. Diabetes Care. 2011; 34(Suppl 2):S210-214.

[PubMed: 21525457] 
Records retrieve from PubMed 'circulating miRNAs and diabetes' $n=103$ 'circulating miRNAs and obesity' $n=23$

'circulating miRNAs and excercice' $n=24$

\section{Records excluded}

Reviews $n=41$

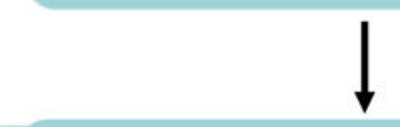

Records after removing reviews, non-expression profiling studies, No report of diabetes, obesity and physical activity, studies with animals $n=36$

Studies selected for meta-analysis after removing duplicates $n=26$

Figure 1.

Flow diagram of study selection. 


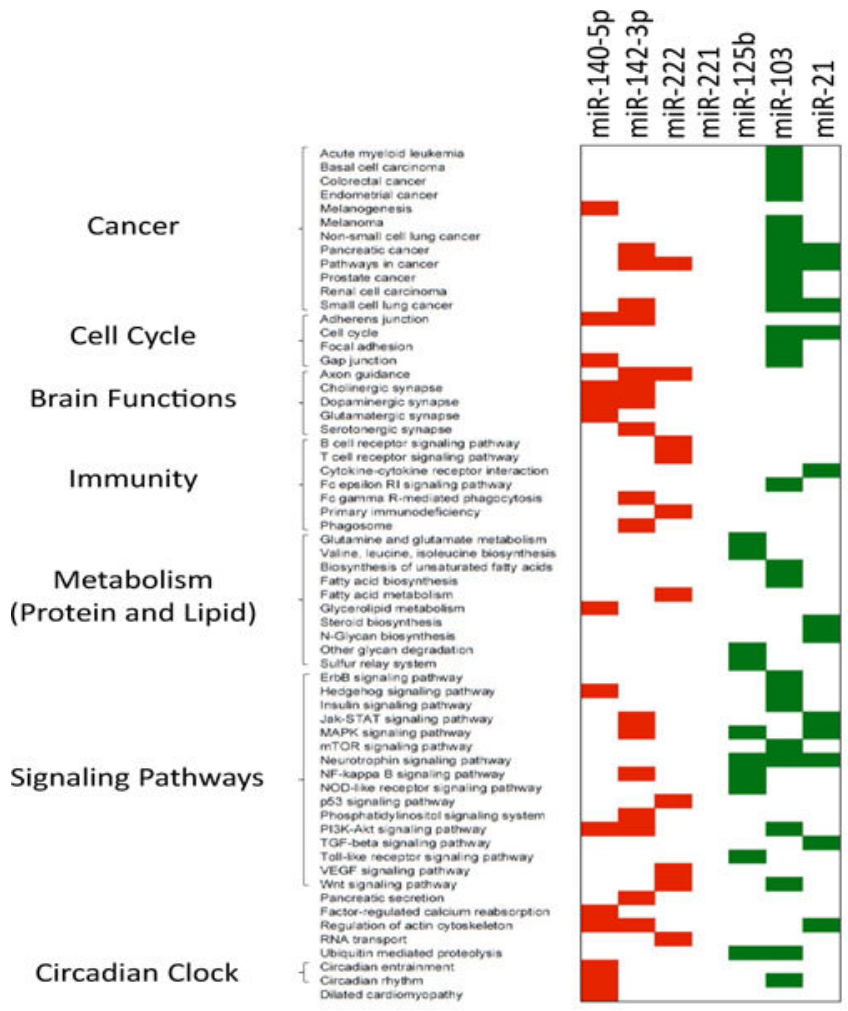

Figure 2.

KEGG pathways significantly enriched in target genes of the 7 miRNAs alteredin blood of obese patients $v s$ healthy lean subjects. Target gene prediction and predicted KEGG pathways are from miRPath (26). MiR-221 did not significantly targeted a specific KEGG pathways. In red, KEGG pathways down-regulated and targeted by up-regulated circulating miRNAs; in green, KEGG pathways upregulated and targeted by downregulated miRNAs. 


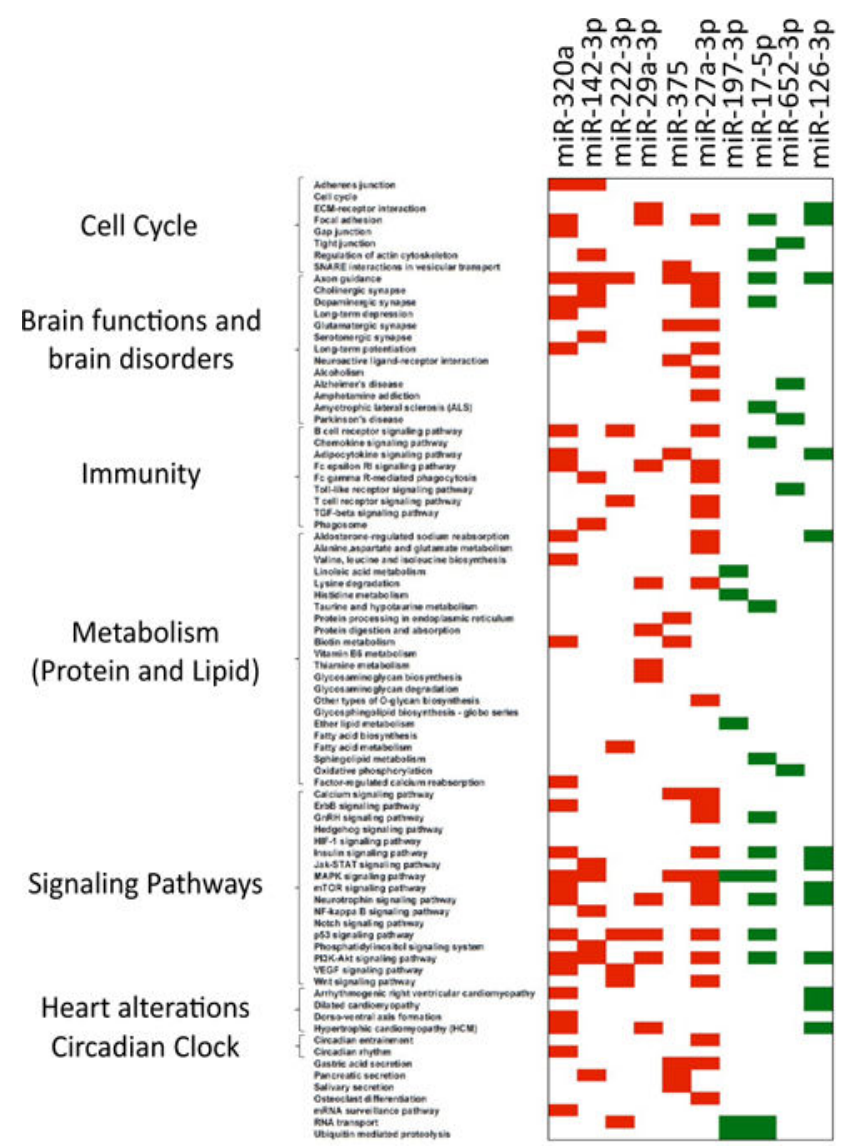

Figure 3.

KEGG pathways significantly enriched in target genes of 10 miRNAs altered in blood of diabetic patients $v s$ healthy subjects. Target gene predictions and predicted KEGG pathways are from miRPath (26). In red, KEGG pathways down-regulated and targeted by upregulated circulating miRNAs; in green, KEGG pathways up-regulated and targeted by down-regulated miRNAs. 


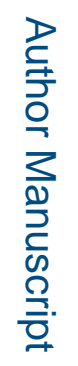

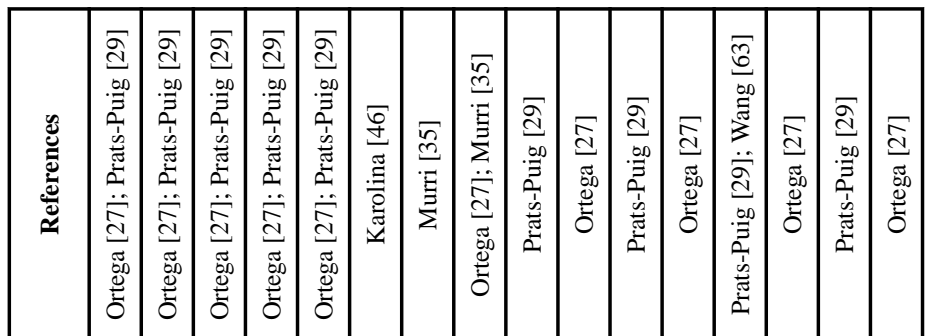

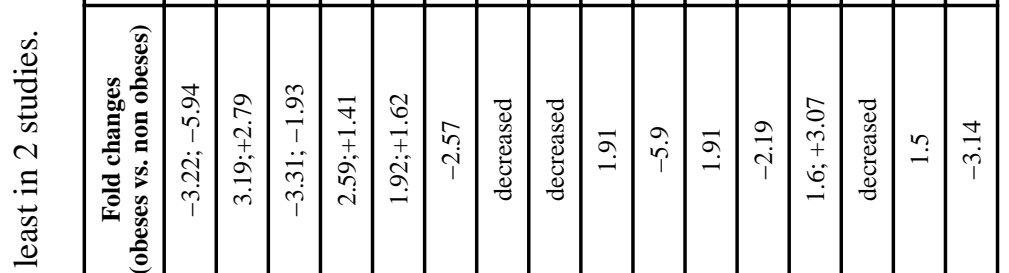

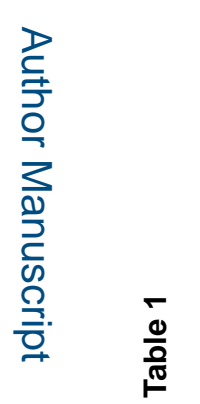

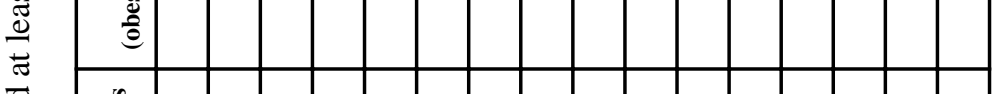

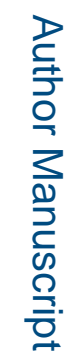

苞

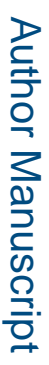

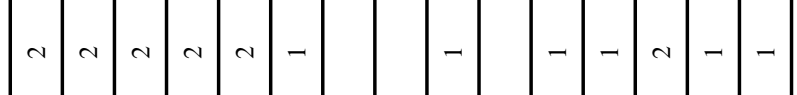

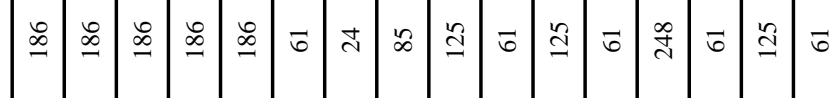

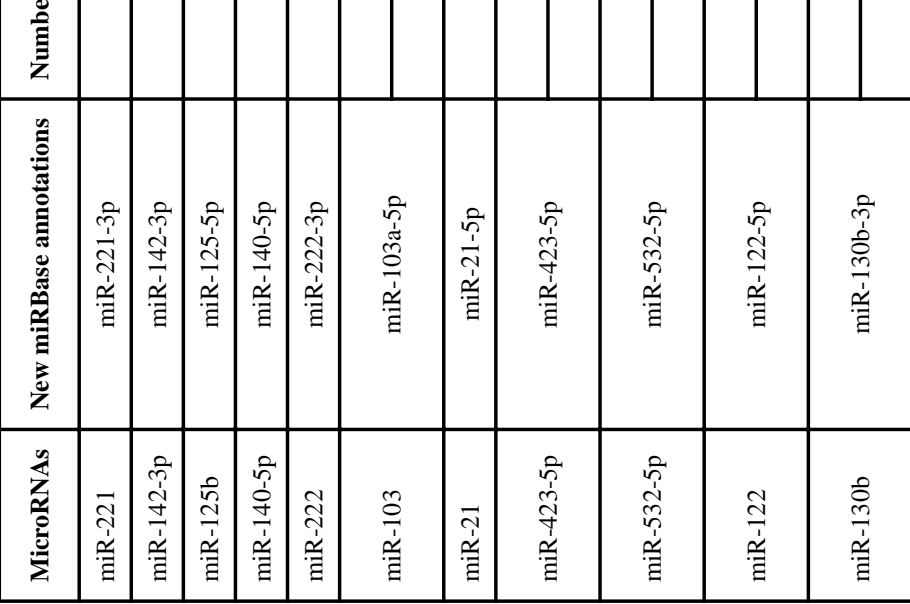

J Mol Biomark Diagn. Author manuscript; available in PMC 2016 June 13. 


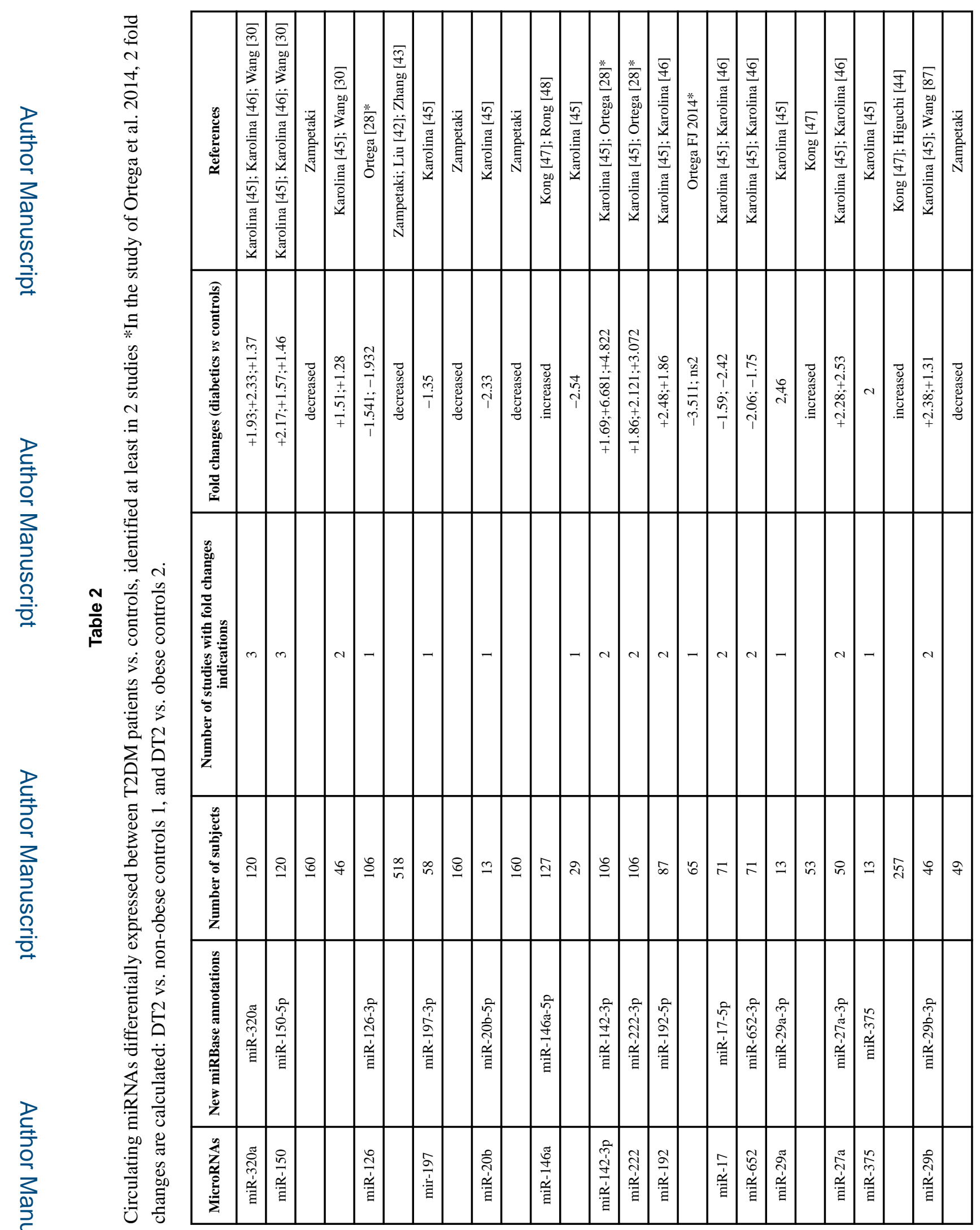




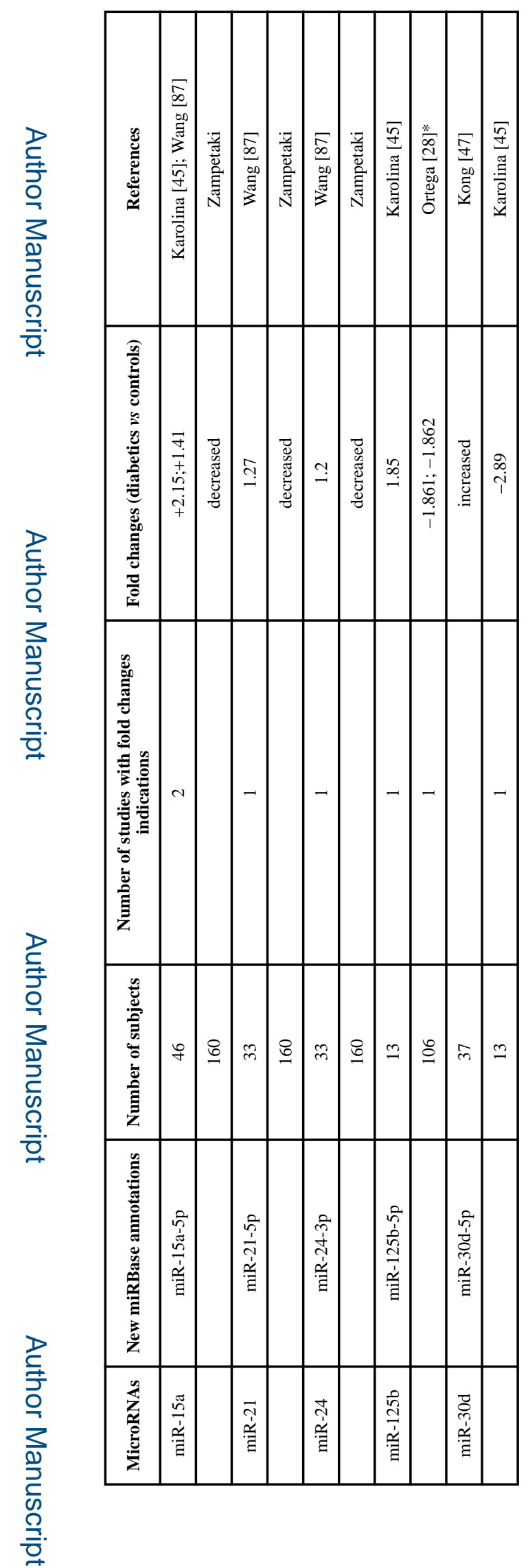

J Mol Biomark Diagn. Author manuscript; available in PMC 2016 June 13. 


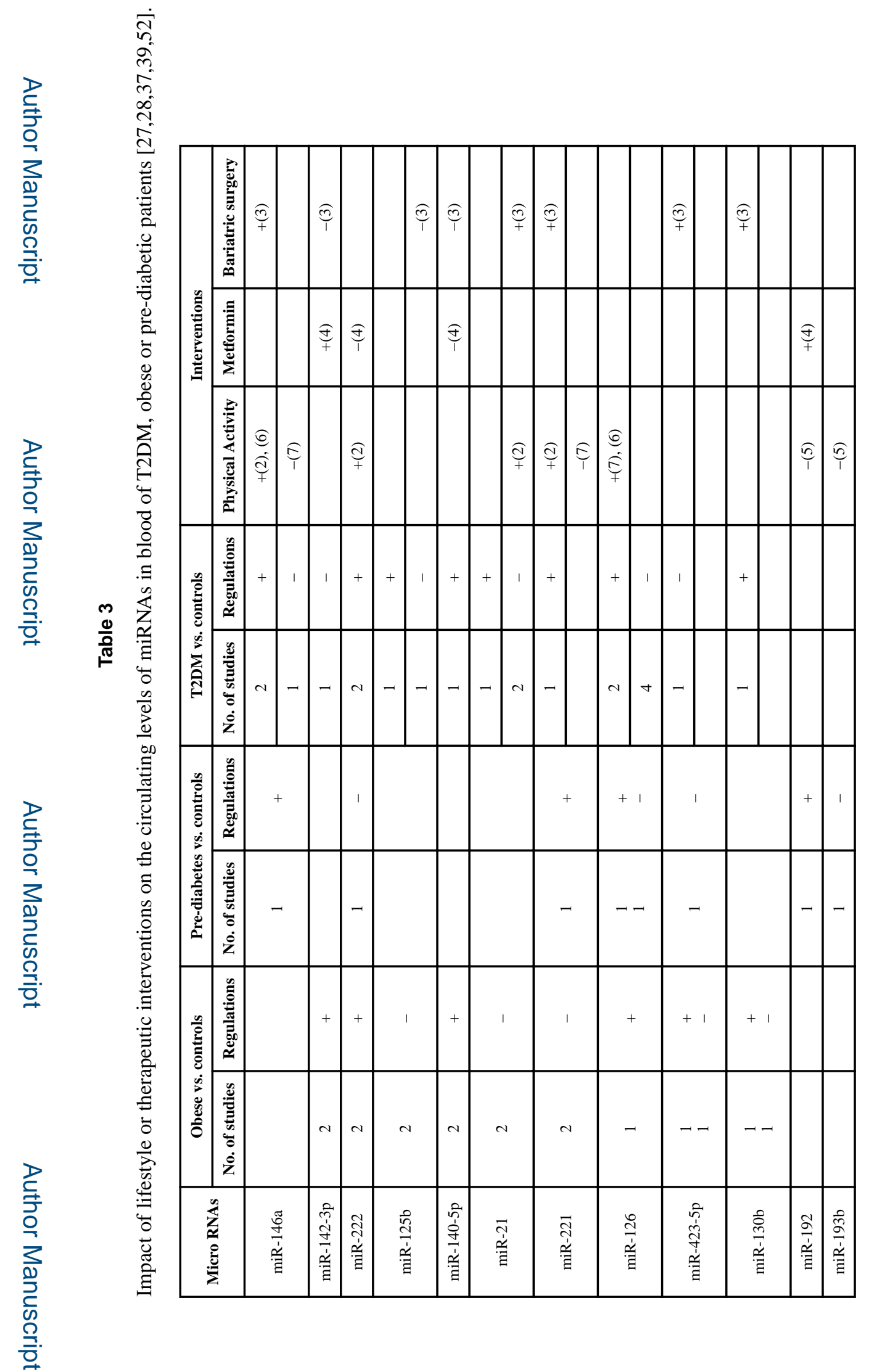

J Mol Biomark Diagn. Author manuscript; available in PMC 2016 June 13. 